\title{
Condensed Matter Researches in Cryospheric Science
}

\author{
Valter Maggi ${ }^{1,2, * \mathbb{C}}$, Cunde Xiao ${ }^{3,4}$ and Augusto Marcelli ${ }^{5,6}$ (1) \\ 1 Earth and Environmental Sciences Department, University of Milano Bicocca, Piazza della Scienza, 1, \\ I-20126 Milano, Italy \\ 2 Istituto Nazionale di Fisica Nucleare, Sezione di Milano-Bicocca, Piazza della Scienza, 2, 20126 Milano, Italy \\ 3 State Key Laboratory of Earth Surface Processes and Resource Ecology, Beijing Normal University, \\ 19 Xinjiekouwai Street, Beijing 100875, China \\ 4 State Key Laboratory of Cryospheric Sciences, Northwest Institute of Eco-Environment and Resources, \\ Chinese Academy of Sciences, Lanzhou 730000, China \\ 5 Istituto Nazionale di Fisica Nucleare, Laboratori Nazionali di Frascati, Via E. Fermi 40, \\ I-00044 Frascati Rome, Italy \\ 6 Rome International Centre for Material Science Superstripes, RICMASS, via dei Sabelli 119A, \\ 00185 Rome, Italy \\ * Correspondence: valter.maggi@unimib.it
}

Received: 5 July 2019; Accepted: 9 July 2019; Published: 12 July 2019

check for updates

Keywords: cryospheric sciences; mineral dust; synchrotron light

\section{Introduction}

The comprehensive understanding of the cryosphere's global biogeochemical cycles represents a great challenge for the present climatic and environmental research on Earth. Many countries are involved in these challenging studies in different strategic areas at the Earth's poles and high mountain regions. China and Italy are strongly involved in these studies, with important results already obtained by their teams. The aim of this special issue, organized together by Chinese and Italian experts in the field, will cover climatic and environmental research studies, based on the detection and characterization of minerals and dust present in ice cores and aerosols in the atmosphere. This interdisciplinary, modern, and strategic research field looks at climate and pollution both at local and global scales [1,2].

Despite the increasing interest and great efforts, in particular over the last decade, there is a lack of consensus on many issues associated with environmental and climatic problems. The amount of studies regarding the environment, mountains and polar glaciers, and the cryosphere in general, are continuously increasing and yet remain far from reaching a conclusion. Ice cores, permafrost, and snow represent extraordinary climatic and environmental information archives that are seriously at risk because of the increasing temperatures on Earth. Research studies using new experimental methods may help in investigating the unique and precious archives with time and spatial resolutions, which were not even imaginable a few years ago. However, new ideas, methods, and approaches are required to improve and extend the characterization of ice and snow, which are extremely complex and fragile materials, and to investigate the very minor amounts of organic and inorganic materials hidden within them. These modern techniques could also be applied to other environmental problems, where the accurate detection and characterization of dust and aerosols present in the atmosphere are highly required.

A substantial improvement in the study of the physical and radiative characteristics of dust particles and in climate models has occurred in order to reliably predict their impact on climate. However, key properties of mineral particles are remain minimally known [3], in that global dust cycle simulations remain poor [4]. Where as, glacial archives, such as polar ice sheets or high-altitude 
mountain glaciers, may offer unique information on modern and past aeolian dust trapped within ice. The background continental dust trapped in high-altitude glaciers and in polar ice sheets provides important information on dust transport in the troposphere, on the relative role of different source areas, and on wind strength. Specific events, such as volcanic eruptions or the impact of extraterrestrial materials [5,6], can be detected in ice cores, along with their effects on climate. These events can also be used to establish ice core chronologies [7].

Dust size distribution is a key issue together with particle morphology, mineralogical composition, and optical characteristics. Mineralogy of dust is required for source identification [8]. In addition, a large assemblage of mineral species within the same matrix and mixing with other poor crystalline fractions, such as volcanic products (i.e., tephra and ashes), organic particles (i.e., spores and bacteria), biomass burning products (i.e., soot), human emissions products (i.e., black carbon, sulfates), and extraterrestrial materials (i.e., micrometeorites) occur. Rare earth elements [9,10] and major elements [11] are related to dust provenance and environmental conditions at dust source areas. Due to the complex composition of dust, it is then mandatory for future climate research based on dust collected from deep ice cores to bring the ultimate limits of all available analytical methods to these studies.

\section{Condensed Matter Applications in Cryospheric Sciences}

\subsection{Advanced Measurement Methods for Cryospheric Sciences}

Due to the complexity of the interaction among cryosphere-atmosphere-lithosphere components, there are currently large uncertainties in the assessment of their physical-chemical properties and source apportionment. In addition, issues about their role in affecting glaciers/snow surfaces radiative effects, Earth's radiation budget, and environmental effects are still under investigation. With the aim of filling this gap, research on this topic has grown a lot in recent years and advanced experimental and modeling approaches have been proposed.

Large facilities, such as synchrotron radiation sources, offer new opportunities to investigations into cryospheric sciences, especially for the analysis of very low concentrations, as for the polar snow and glacier samples. For example, LISA (Linea Italiana per la Spettroscopia di Assorbimento di raggi $X$ ) is the beamline of the Italian Collaborating Research Group (CRG) at the European Synchrotron Radiation Facility (ESRF) dedicated to X-ray absorption spectroscopy (XAS). The beamline covers a wide energy range, $4<E<90 \mathrm{keV}$, which offers the possibility to probe $\mathrm{K}$ and $\mathrm{L}$ edges of elements that are heavier than $\mathrm{Ca}[12]$.

Furthermore, Cibin et al. [13] developed instrumentation and protocols to optimize the collection of synchrotron radiation X-ray fluorescence, $\mathrm{X}$-ray absorption spectroscopy, and X-ray powder diffraction data on ice core and possible source areas mineral dust samples, at the Diamond Light Source Facility (UK).

Many spectroscopic methods allow the characterization of the structure and electronic structure of samples, while the scattering/diffraction methods enable the determination of crystalline structures of either organic or inorganic systems. Moreover, imaging methods offer an unprecedented spatial resolution of samples, revealing their morphology and even their inner structure. In this issue, Xu et al. [14] introduce the synchrotron radiation facilities now available in mainland China, and the perspectives of synchrotron radiation-based methods suitable for investigating ice, snow, aerosols, dust, and other samples of cryospheric origin, i.e., deep ice cores, permafrost, filters, etc. The goal is to deepen the understanding of cryospheric sciences through increased collaboration between the synchrotron radiation community and scientists working in polar areas or involved in correlated environmental problems.

Nowadays, important research studies can be performed using conventional sources too. Indeed, the combination of low-power conventional sources and polycapillary optics allows the assembly of a prototype, which can provide a quasi-parallel intense beam for detailed X-ray spectroscopic analysis of extremely low concentrated samples. Cappuccio et al. [15] report the applications of the total external 
X-ray fluorescence (TXRF) station, a prototype assembled at the XLab Frascati laboratory (XlabF) at the INFN National Laboratories of Frascati (INFN LNF). This laboratory has been established as a facility to study, design, and develop X-ray optics, in particular, polycapillary lenses, as well as to perform $\mathrm{X}$-ray experiments for both elemental analysis and tomography.

The analysis of particulate matter (PM) in dilute solutions is an important target for environmental, geochemical, and biochemical research. Macis et al. [16] show how the microdrop technology may allow the control, through the evaporation of small droplets, of the deposition of insoluble materials dispersed in a solution on a well-defined area with a specific spatial pattern. Using this approach, the superficial density of the deposited solute can be accurately controlled, and it is possible to deposit an extremely reduced amount of insoluble materials, in the order of few $\mu \mathrm{g}$ on a confined area, thus allowing a relatively high superficial density to be reached within a limited time.

\subsection{High Latitude-High Altitude Mineral Dust Atmospheric Transport}

Mineral dust has a large impact on the Earth's radiative budget, ocean, and continental fertilization, as well as influencing many elemental biogeochemical cycles. Iron is well known to be a limit of the phytoplankton population's biomass in extensive regions of the ocean, which are referred to as high-nutrient low-chlorophyll (HNLC) regions, but iron speciation in continental soils is still poorly understood.

Liu et al. [17] investigated inorganic and organic standard substances, diluted mixtures of common Fe minerals in insoluble dust in snow from the Laohugou No.12 glacier, and sand including soil and moraine samples that were collected from western China using X-ray absorption near-edge structure (XANES) spectroscopy. Reference compounds showed that these samples contain only three mineral species: $\mathrm{Fe}_{2} \mathrm{O}_{3}$ (hematite), $\mathrm{Fe}_{3} \mathrm{O}_{4}$ (magnetite), biotite, and the chemical compound ferrous oxalate dihydrate (FOD), not yet recognized as a mineral species. These substances show a significant altitude effect depending on the elevation of the sampled snow samples.

Two contributions present the mineral dust characterization from Antarctic ice cores. Based on the XANES measurements, Fe K-edge spectra were collected on aeolian dust in the TALos Dome Ice CorE drilling project (TALDICE) ice core drilled in the peripheral East Antarctic plateau, as well as on Southern Hemisphere potential source area samples, by Maggi et al. [18]. While South American sources show, as expected, a progressive increase in Fe oxidation with decreasing latitude, Antarctic sources show Fe oxidation levels higher than expected in such a cold polar environment, probably because of their very high exposure ages. Results from the TALDICE dust samples are compatible with a South American influence at the site during the marine isotopic stage 2 (MIS2), the last and coldest phase of the last glacial period, in particular from Patagonia and Tierra del Fuego. However, a contribution from Australia and/or local Antarctic sources cannot be ruled out. Finally, important changes also occurred during the deglaciation and in the Holocene, when the influence of Antarctic local sources seems to become progressively more important in more recent times. Baccolo et al. [19] investigate the possibility of finding a stratigraphically intact ice sequence with a potential basal age exceeding one million years in Antarctica, and present here preliminary results on two sets of samples retrieved from the TALDICE ice core. A first set is composed of samples from the stratigraphically intact upper part of the core, the second by samples retrieved from the deeper part of the core that remains undated. Two techniques based on synchrotron radiation allowed characterization of the dust samples, showing that mineral particles entrapped in the deepest ice layers display altered elemental composition and anomalies concerning iron geochemistry, besides being affected by inter-particle aggregation.

Speranza et al. [20] applied compositional data analysis on mineral element concentrations, i.e., $\mathrm{Al}, \mathrm{Ti}, \mathrm{Si}, \mathrm{Ca}, \mathrm{Mg}, \mathrm{Fe}, \mathrm{Sr}$ content in $\mathrm{PM}_{10}, \mathrm{PM}_{2.5}$, and $\mathrm{PM}_{1}$ simultaneous measurements at three characteristic environmental sites: kerbside, background, and rural site. Different possible sources of mineral trace elements affecting the PM in the considered sites were highlighted. Particularly, results show that compositional data analysis allows for the assessment of chemical/physical differences among mineral element concentrations of PM. These differences can be related to both different kinds of involved mineral sources and different mechanisms of accumulation/dispersion of PM at those sites. 


\subsection{Climatic Impact on the Cryospheric Environments}

Ding et al. [21] report climate changes of Ny-Ålesund, Svalbard, a representative location of the northern North Atlantic sector of the Arctic, based on observational records from 1975 to 2014 . Correlation among records of Ny-Ålesund and global HadCRUT4 datasets indicate the likelihood that the Arctic was experiencing a hiatus pattern, which just appeared later than at low to mid latitudes due to transport processes of atmospheric circulations and ocean currents, heat storage effect of cryospheric components, multidecadal variability of Arctic cyclone activities, etc. This case study provides a real new perspective on the global warming hiatus/slowdown debate.

Glaciers are important fresh-water reservoirs for our planet. Although they are often located at high elevations or in remote areas, glacial ecosystems are not pristine, as many pollutants can undergo long-range atmospheric transport and be deposited on glacier surface, where they can be stored for long periods of time, and then be released into the down-valley ecosystems. Pittino et al. [22] review studies on cryoconite holes, which occur on the surface of most glaciers. They are small ponds filled with water and a layer of sediment, named cryoconite, at the bottom. Indeed, these are hotspot environments for biodiversity on glacier surface as they host metabolically active bacterial communities that include generalist taxa able to degrade pollutants. These studies have also revealed that bacteria play a significant role in pollutant degradation in these habitats and can be positively selected in contaminated environments.

\section{Concluding Remarks}

These results present highlights of some of the most recent advances in cryospheric studies, especially in relation to mineral dust and aerosols in the atmosphere. They evidence the complexity of chemical-physical processes involving solid compounds occurring in glacier, snow, and permafrost environments, covering different aspects such as spatial and temporal trends, as well as the impact of the mineral and non-mineral particles. These studies also demonstrate the need for collaborative interdisciplinary and transnational efforts to better understand the challenges of the present climatic and environmental research studies on Earth, but also out of the Earth's system. The results show that recent advances in measurement techniques and source apportionment are powerful and sophisticated tools that may provide novel high-quality scientific information but represent only the first challenging step.

Author Contributions: All the authors contributed equally.

Funding: This research received no external funding.

Acknowledgments: We express our thanks to all authors that contributed to this special issue, to the journal Condensed Matter that hosts these contributions and to the MDPI staff for their continuous support.

Conflicts of Interest: The authors declare no conflict of interest.

\section{References}

1. Schulz, M.; Prospero, J.M.; Baker, A.R.; Dentener, F.; Ickes, L.; Liss, P.S.; Mahowald, N.M.; Nickovic, S.; García-Pando, C.P.; Rodríguez, S.; et al. Atmospheric Transport and Deposition of Mineral Dust to the Ocean: Implications for Research Needs. Environ. Sci. Technol. 2012, 46, 10390-10404. [CrossRef] [PubMed]

2. Shi, Z.B.; Krom, M.D.; Jickells, T.D.; Bonneville, S.; Carslaw, K.S.; Mihalopoulos, N.; Baker, A.R.; Benning, L.G. Impacts on iron solubility in the mineral dust by processes in the source region and the atmosphere: A review. Aeolian Res. 2012, 5, 21-42. [CrossRef]

3. Formenti, P.; Schutz, L.; Balkanski, Y.; Ebert, M.; Kandler, K.; Petzold, A.; Scheuvens, D.; Weinbruch, S.; Zhang, D. Recent progress in understanding physical and chemical properties of African and Asian mineral dust. Atmos. Chem. Phys. 2011, 11, 8231. [CrossRef]

4. Huneeus, N.; Schulz, M.; Balkanski, Y.; Griesfeller, J.; Prospero, J.; Kinne, S.; Bauer, S.; Boucher, O.; Chin, M.; Dentener, F.; et al. Global dust model intercomparison in AeroCom phase I. Atmos. Chem. Phys. 2011, 11, 7781. [CrossRef]

5. Narcisi, B.; Petit, J.R.; Engrand, C. First discovery of meteoritic events in deep Antarctic (EPICA-Dome C) ice cores. Geophys. Res. Lett. 2007, 34, L15502. [CrossRef] 
6. Narcisi, B.; Petit, J.R.; Delmonte, B.; Basile-Doelsch, I.; Maggi, V. Characteristics and sources of tephra layers in the EPICA-Dome $\mathrm{C}$ ice record (East Antarctica): Implications for past atmospheric circulation and ice core stratigraphic correlations. Earth Planet. Sci. Lett. 2005, 239, 253. [CrossRef]

7. Parrenin, F.; Barnola, J.M.; Beer, J.; Blunier, T.; Castellano, E.; Chappellaz, J.; Dreyfus, G.; Fischer, H.; Fujita, S.; Jouzel, J.; et al. The EDC3 chronology for the EPICA Dome, C. ice core. Clim. Past 2007, 3, 485. [CrossRef]

8. Maggi, V. Mineralogy of atmospheric microparticles deposited along the Greenland Ice Core Project ice core. J. Geophys. Res. 1997, 102, 725. [CrossRef]

9. Wegner, A.; Gabrielli, P.; Wilhelms-Dick, D.; Ruth, U.; Kriews, M.; De Deckker, P.; Barbante, C.; Cozzi, G.; Delmonte, B.; Fischer, H. Change in dust variability in the Atlantic sector of Antarctica at the end of the last deglaciation. Clim. Past 2012, 8, 135-147. [CrossRef]

10. Gabrielli, P.; Wegner, A.; Petit, J.R.; Delmonte, B.; De Deckker, P.; Gaspari, V.; Fischer, H.; Ruth, U.; Kriews, M.; Boutron, C.; et al. A major glacial-interglacial change in aeolian dust composition inferred from Rare Earth Elements in Antarctic ice. Quat. Sci. Rev. 2010, 29, 265. [CrossRef]

11. Marino, F.; Castellano, E.; Ceccato, D.; De Deckker, P.; Delmonte, B.; Ghermandi, G.; Maggi, V.; Petit, J.R.; Revel, M.; Udisti, R. Defining the geochemical composition of the EPICA Dome C ice core dust during the last glacial-interglacial cycle. Geochem. Geophys. Geosyst. 2008, 9, Q10018. [CrossRef]

12. Puri, A.; Lepore, G.O.; d'Acapito, F. The New Beamline LISA at ESRF: Performances and Perspectives for Earth and Environmental Sciences. Condens. Matter 2019, 4, 12. [CrossRef]

13. Cibin, G.; Marcelli, A.; Maggi, V.; Baccolo, G.; Hampai, D.; Robbins, P.; Liedl, A.; Polese, C.; D’Elia, A.; Macis, S.; et al. Synchrotron Radiation Research and Analysis of the Particulate Matter in Deep Ice Cores: An Overview of the Technical Challenges. Condens. Matter 2019, 4, 61. [CrossRef]

14. Xu, W.; Du, Z.; Liu, S.; Zhu, Y.; Xiao, C.; Marcelli, A. Perspectives of XRF and XANES Applications in Cryospheric Sciences Using Chinese SR Facilities. Condens. Matter 2018, 3, 29. [CrossRef]

15. Cappuccio, G.; Cibin, G.; Dabagov, S.B.; Di Filippo, A.; Piovesan, G.; Hampai, D.; Maggi, V.; Marcelli, A. Challenging X-ray Fluorescence Applications for Environmental Studies at XLab Frascati. Condens. Matter 2018, 3, 33. [CrossRef]

16. Macis, S.; Cibin, G.; Maggi, V.; Baccolo, G.; Hampai, D.; Delmonte, B.; D’Elia, A.; Marcelli, A. Microdrop Deposition Technique: Preparation and Characterization of Diluted Suspended Particulate Samples. Condens. Matter 2018, 3, 21. [CrossRef]

17. Liu, S.; Xiao, C.; Du, Z.; Marcelli, A.; Cibin, G.; Baccolo, G.; Zhu, Y.; Puri, A.; Maggi, V.; Xu, W. Iron Speciation in Insoluble Dust from High-Latitude Snow: An X-ray Absorption Spectroscopy Study. Condens. Matter 2018, 3, 47. [CrossRef]

18. Maggi, V.; Baccolo, G.; Cibin, G.; Delmonte, B.; Hampai, D.; Marcelli, A. XANES Iron Geochemistry in the Mineral Dust of the Talos Dome Ice Core (Antarctica) and the Southern Hemisphere Potential Source Areas. Condens. Matter 2018, 3, 45. [CrossRef]

19. Baccolo, G.; Cibin, G.; Delmonte, B.; Hampai, D.; Marcelli, A.; Di Stefano, E.; Macis, S.; Maggi, V. The Contribution of Synchrotron Light for the Characterization of Atmospheric Mineral Dust in Deep Ice Cores: Preliminary Results from the Talos Dome Ice Core (East Antarctica). Condens. Matter 2018, 3, 25. [CrossRef]

20. Speranza, A.; Caggiano, R.; Pavese, G.; Summa, V. The Study of Characteristic Environmental Sites Affected by Diverse Sources of Mineral Matter Using Compositional Data Analysis. Condens. Matter 2018, 3, 16. [CrossRef]

21. Ding, M.; Wang, S.; Sun, W. Decadal Climate Change in Ny-Ålesund, Svalbard, A Representative Area of the Arctic. Condens. Matter 2018, 3, 12. [CrossRef]

22. Pittino, F.; Ambrosini, R.; Azzoni, R.S.; Diolaiuti, G.A.; Villa, S.; Gandolfi, I.; Franzetti, A. Post-Depositional Biodegradation Processes of Pollutants on Glacier Surfaces. Condens. Matter 2018, 3, 24. [CrossRef]

(C) 2019 by the authors. Licensee MDPI, Basel, Switzerland. This article is an open access article distributed under the terms and conditions of the Creative Commons Attribution (CC BY) license (http://creativecommons.org/licenses/by/4.0/). 